\title{
Dynamic strength of distill water and lake water ice at high strain rates
}

\author{
Xianqian Wu ${ }^{\text {b }}$, Vikas Prakash ${ }^{\text {a, * }}$ \\ ${ }^{a}$ Department of Mechanical and Aerospace Engineering, Case Western Reserve University, Cleveland, OH 44106, USA \\ ${ }^{\mathrm{b}}$ Key Laboratory of Mechanics in Fluid Solid Coupling Systems, Institute of Mechanics, Chinese Academy of Sciences, Beijing 100190, PR China
}

\section{A R T I C L E I N F O}

Article history:

Received 7 August 2014

Received in revised form

9 September 2014

Accepted 30 September 2014

Available online 7 October 2014

Keywords:

Dynamic compression of ice

Modified split Hopkinson pressure bar

Uniaxial compression and oblique impact

Strain rate sensitivity of ice

Peak stress of ice

\begin{abstract}
A B S T R A C T
In the present study, a modified split Hopkinson pressure bar (SHPB) is employed to investigate dynamic response of lake water ice and distilled water ice under dynamic uniaxial compression and combined compression and shear loading (oblique impact) at strain rates in the range of $80-600 \mathrm{~s}^{-1}$ and at test temperature of $-15^{\circ} \mathrm{C}$. For both ice the uniaxial dynamic compressive strengths show positive strain rate sensitivity over the range of strain rates employed. The strength of lake water ice under uniaxial compression is observed to be consistently higher when compared to distill water ice. Moreover, the peak stresses of both lake water ice and distill water ice are observed to be consistently lower under oblique impact when compared to those obtained under uniaxial compression. In addition, for oblique impact the sensitivity of the logarithmic of peak stress to the logarithm of the applied strain rate for lake water and distilled water ice is higher than that obtained under uniaxial compression. A consistent feature observed in the post-peak stress regime of both lake water ice and distill water ice is the presence of a long tail in their dynamic stress versus strain curves, indicating complex inter-particle interactions in the fragmented ice after the attainment of the peak stresses. This residual strength of pulverized/fragmented ice can be best understood by considering the damaged/fragmented ice as an assemblage of wet highly-fragmented granular material created by adiabatic heating during grain-to-grain frictional sliding and/or impact-induced melting, held together by ice melt and/or recrystallization in the post-peak-stress regime.
\end{abstract}

() 2014 Elsevier Ltd. All rights reserved.

\section{Introduction}

Better understanding of dynamic behavior of ice is important in the fields of climatology, glaciology, and in engineering and materials sciences. For instance, the fracture of sea ice, induced by compressive loading due to wind and ocean currents, not only threatens the integrity of off-shore structures but also plays a significant role in both local and global climate. There is a considerable body of knowledge in the literature that addresses mechanical behavior of clean ice, i.e. ice free from a significant volume fraction of foreign particulates. However, there is little or no data on the dynamic behavior of dirty ice, which exists widely on earth. In view of this, in this paper we report results of an experimental investigation undertaken at Case Western Reserve University (CWRU) to the dynamic behavior of lake water ice at high strain rates and compare it with high strain rate data on distilled water ice. The

\footnotetext{
* Corresponding author. Tel.: +1 (216) 8342646.

E-mail address: vikas.prakash@case.edu (V. Prakash).
}

results obtained in the study can be used to validate and/or develop new material models for impact analyses involving ice, which can be used for better understanding the severity of sea/lake ice impacts on off-shore structures, vehicle tire-ice interactions in freezing terrains, hail impact damage/resistance, to name a few.

The mechanical behavior of ice is complex. Ice can be regarded as a class of materials rather than a single specific material with well-defined properties. It can exist in thirteen different crystal structures and two amorphous states depending upon its growth temperature and pressure conditions. A large body of work exists that describes the compressive and tensile behavior of clean ice [1-7], and its fracture properties [8-12]. Most of these studies focus on creep and quasi-static deformation behavior of distilled water ice, and like many other brittle materials ice has been found to be stronger in compression than in tension. However, unlike most brittle materials ice exhibits brittle behavior up to its melting point even at relatively low strain rates [6].

The ductile to brittle transition in distill water ice is understood to occur at a strain rate of $10^{-3} \mathrm{~s}^{-1}$ at a temperature of $-10^{\circ} \mathrm{C}$. At higher strain rates, there are relatively few studies on the 
mechanical behavior of ice. The studies by Dutta [13] and Dutta et al. [14] suggest that strength of ice at high strain rates is lower than that obtained at quasi-static deformation conditions. Kim and Keune [15], using the split Hopkinson pressure bar (SHPB) [16,17] concluded that in the strain rate range from 400 to $2600 \mathrm{~s}^{-1}$, the dynamic compressive strength of ice is essentially constant at a level of 19.7 MPa. Other studies at higher strain rates show that the compressive strength of ice increases with increasing strain rates: the work by Jones [18] shows that the compressive strength of ice increases with increasing strain rates over the strain rate range $10^{-1}-10 \mathrm{~s}^{-1}$, although the data shows considerable scatter. The study by Schulson et al. [7] shows similar behavior in the strain rate range from $10^{-2}$ to $1.6 \mathrm{~s}^{-1}$. In a more recent study, Shazly et al. [19-21] studied the dynamic behavior of single and polycrystalline distilled water ice using SHPB at a range of strain rates from 60 to $1400 \mathrm{~s}^{-1}$. The compressive strengths of both single and polycrystalline ice were observed to increase with increasing strain rates. In addition, the results indicated that the ice samples do not catastrophically lose their load carrying capacity even after the attainment of the peak stress during dynamic compression.

All the aforementioned studies on dynamic behavior of ice have been conducted on distill water ice. However, the dynamic compressive behavior of lake (dirty) ice, i.e. ice that includes foreign particulates of considerable volume fraction, is largely unknown. It is expected that the dynamic behavior of lake water ice will different from that of distill water ice due to the presence of chemicals and foreign particulates. Available literature on creep behavior of dirty ice suggests that barring low concentration of ultra-fine $(\sim 15 \mathrm{~nm})$ silica particulates, which appear to strengthen ice, larger size (a few hundred micrometers) particles of the order of a small volume percentage actually weaken ice [22-24]. However, the effects of foreign particulates on compressive behavior of ice at higher strain rates are largely uncertain.

With this as a motivation, an experimental study was undertaken at Case Western Reserve University to better understand the dynamic mechanical behavior of lake water ice at elevated strainrates. In the study, the conventional split Hopkinson pressure bar was modified to accommodate low-temperature testing of lake water ice at elevated strain rates. Disk shaped ice specimens with flat and parallel end faces were grown by freezing in an ice chamber. The effects of strain rate on the dynamic uniaxial compressive behavior and the combined compressive and shear behavior of lake water ice were systematically investigated and compared with that obtained for distill water ice specimens grown using a similar procedure.

The paper is organized as follows. In Section 2, the experimental procedure used for the growth of the ice samples as well as the extension of the split Hopkinson pressure bar method for low temperature testing is described. In Section 3, the experimental details and corresponding experimental results on lake water ice and distilled water ice are provided. In Section 4, experimental results for lake water ice and distilled water ice at different strain rates are compared, and discussion relevant to the experimental results is provided.

\section{Experimental methods}

\subsection{Ice specimens}

In the present study, disk shaped ice samples of $19 \mathrm{~mm}$ in diameter and approximately $3 \mathrm{~mm}$ in thickness were utilized to conduct the dynamic compression experiments. Although the ice samples were thin when compared to their diameter, which could constrain radial displacements in the sample during loading due to frictional effects at the specimen/bar interface, studies by Shazly et al. $[19,20]$ have shown that such effects are negligible since frictional resistance between ice and aluminum inserts is minimal at high sliding rates [25-28] and also because of the relatively small slip (lateral strains) expected during failure of brittle ice.

Besides frictional effects, the stress wave loading used in split Hopkinson pressure bar experiments can cause inertia to have an influence on the measured sample properties, particularly at high strain rates [29]. For a sample with diameter $d$, and an initial length by diameter ratio $l_{o} / d_{o}$, the stresses measured by the output bar, $\sigma_{\text {measured }}$ can be expressed as

$$
\begin{aligned}
\sigma_{\text {measured }}-\sigma_{y}= & \rho d^{2} \dot{\varepsilon}^{2}\left[\frac{1}{64}+\frac{1}{6}\left(\frac{l_{o}}{d_{o}}\right)^{2}\right]-\rho d^{2} \ddot{\varepsilon}\left[\frac{1}{32}-\frac{1}{6}\left(\frac{l_{o}}{d_{o}}\right)^{2}\right] \\
& -\frac{\rho l \dot{v}}{2}
\end{aligned}
$$

where, $\sigma_{y}$ is the actual yield stress of the material, $\rho$ is the density of the material, and $v$ is the velocity of the interface between the specimen and the output bar. In a typical SHPB experiment with a nearly constant strain rate, the magnitude of the second term is much smaller when compared the first term, and the magnitude of the third term is generally small for materials which do not exhibit very high strain hardening and/or softening. Ignoring the second and third terms, a typical relative error in flow stress measurement due to inertia can be expressed as

$$
\frac{\sigma_{\text {measured }}-\sigma_{y}}{\sigma_{y}}=\frac{\rho d^{2}}{\sigma_{y}} \dot{\varepsilon}^{2}\left[\frac{1}{64}+\frac{1}{6}\left(\frac{l_{o}}{d_{o}}\right)^{2}\right]
$$

For the ice samples used in the present study, using Eq. (2) the error due to inertia can be approximated to be $0.001 \%$, where we have used the ice density to be $\sim 897 \mathrm{~kg} / \mathrm{m}^{3}$, diameter of the sample $\sim 19 \mathrm{~mm}$, $l_{o} / d_{o}$ ratio of 0.16 , average strain rates $250 \mathrm{~s}^{-1}$, and $\sigma_{y} \sim 30 \mathrm{MPa}$.

As shown in Fig. 1, the ice samples were grown between two flat and smooth cylindrical aluminum inserts spaced at a pre-determined distance (equivalent to the thickness of the ice specimens) and then wrapped with masking tape to form a mold. For oblique impact experiments the ice samples were grown between two $20^{\circ}$ (angle $\theta$ ) inclined aluminum inserts with flat end-surfaces. A small hole is introduced in the masking tape to fill the cavity between the two inserts with test water to grow the ice samples. The hole also acts as a drain for water from the compartment when it freezes. A precision matched pair of Vee blocks were used to ensure perfect alignment between the two inserts. The whole assembly was then placed inside a freezer at $-15{ }^{\circ} \mathrm{C}$ to grow the ice samples. The ice nucleation and growth process lasts approximately $30 \mathrm{~min}$;

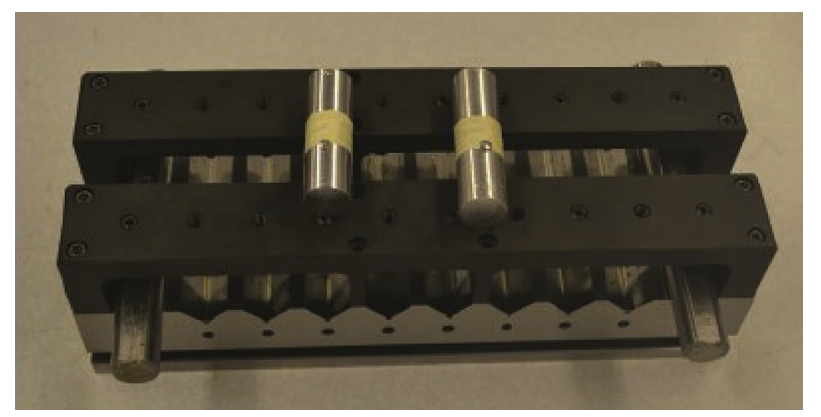

Fig. 1. Method for growing ice specimens for normal and oblique impact experiments Two precision matched Vee-blocks were used to ensure perfect alignment between the inserts. 
Table 1

Chemical composition of lake water.

\begin{tabular}{|c|c|c|c|c|c|}
\hline \multicolumn{2}{|c|}{ Testing information } & \multicolumn{4}{|c|}{ Regulatory information } \\
\hline Analyte name & Result (mg/L) & $\begin{array}{l}\mathrm{RL} \\
(\mathrm{mg} / \mathrm{L})\end{array}$ & $\begin{array}{l}\mathrm{MCL} / \mathrm{AL} \\
(\mathrm{mg} / \mathrm{L})\end{array}$ & Method & CAS\# \\
\hline $\begin{array}{l}\text { Coliform } \\
\text { organisms } \\
\text { per } 100 \mathrm{~mL}\end{array}$ & Not detected & N.A. & N.A. & SM 9223 B & TC-00-B \\
\hline Chloride & 66 & 4 & N.A. & SM 4500-CI E & $7647-14-5$ \\
\hline Fluoride & Not detected & 0.1 & 4.0 & SM 4500 FC & $16984-48-8$ \\
\hline $\begin{array}{l}\text { Hardness } \\
\text { as } \mathrm{CaCO}_{3}\end{array}$ & 164 & 10 & N.A. & SM 2340 C & HARD-00-C \\
\hline Iron & 2.4 & 0.1 & N.A. & SM $3500 \mathrm{FeB}$ & $7439-89-6$ \\
\hline Nitrate as $\mathrm{N}$ & Not detected & 0.4 & 10 & SM 4500 NO3F & $14797-55-8$ \\
\hline Nitrite as $\mathrm{N}$ & Not detected & 0.05 & 1 & SM 4500 NO3F & $14797-65-0$ \\
\hline Sodium & 57 & 5 & N.A. & SM 3111B & $7440-23-5$ \\
\hline Sulfate & 24 & 5 & N.A. & SM 4500 SO4E & $14808-79-8$ \\
\hline
\end{tabular}

however, the specimens are kept in the freezer for at least 6 more hours before they are taken out of the freezer for testing. Due to the high thermal conductivity of the aluminum inserts the ice crystals were observed to consistently nucleate from the inner faces of the aluminum inserts inside the molds and grow inwards towards the center of the compartment. This growth process results in a noticeable interface at the mid-plane of the ice specimens.

The composition of the lake (dirty) water is provided in Table 1. The water contains a variety of chemical impurities, such as, chlorides, calcium carbonate, iron, sodium and sulfate of considerable volume fractions.

The microstructure of a natural ice formation depends on its thermal-mechanical history. Grain sizes of frozen ice are typically around $1 \mathrm{~mm}-20 \mathrm{~mm}$, and the grain shape varies from equiaxed to elongated. In the present study, both lake water and distill water ice samples were grown directly unidirectional solidification of water. We observed the microstructure of the specimens by examining thin-sections under direct light and/or between crossed polarizing filters. Under polarized light, the grains exhibited interference colors and could be easily differentiated. Typical microstructures of the distill water ice and lake water ice specimens were essentially indistinguishable from each other under the low magnification optical microscope used in the analysis, and are shown in Fig. 2 for distill water ice. In both cases the ice samples were found to be polycrystalline, and the ice crystals preferentially nucleated from the aluminum inserts creating small equiaxed grains up to approximately $1.5 \mathrm{~mm}$ in diameter. These grains were observed to grow from the two insert ends towards the mid-plane of the sample forming columnar-shaped grains elongated in the growth direction, reminiscent of metallic ingots. The resulting grains were approximately $3 \mathrm{~mm}$ in diameter by $5 \mathrm{~mm}$ in length for the largest grains. The transverse section of the ice specimen, shown in Fig. 2(b), indicates that the large grains have extensive substructures. It is to be noted that Fig. 2 shows microstructure of distill water ice sample with thickness of approximately $10 \mathrm{~mm}$. In the SHPB experiments (described later) the majority of the specimens were $3 \mathrm{~mm}$ in thickness. However, the microstructure of such thin ice samples could not be analyzed because of the limitations of the sample size (thermal inertia) that could be used with our optical microscope.

\subsection{Experimental methods}

In the present study, the conventional split Hopkinson pressure bar (SHPB) apparatus was modified to investigate high strain rate compressive behavior of distill water ice and lake water ice samples at sub-zero test temperature of $\sim-15^{\circ} \mathrm{C}$ and strain rates varying from 80 to $600 \mathrm{~s}^{-1}$ [30]. The schematic of the modified SHPB is shown in Fig. 3. The facility comprises a striker bar, an incident bar, and a transmitter bar, all made from $19.05 \mathrm{~mm}$ diameter highstrength 7075-T6 aluminum alloy having a nominal yield strength of approximately $500 \mathrm{MPa}$. The length of the striker bar is about $0.3 \mathrm{~m}$, while the lengths of the incident and transmitter bars are approximately $1.8 \mathrm{~m}$ and $2 \mathrm{~m}$, respectively. The striker bar was accelerated using a compressed air gas-gun to impact velocities in the range of 3-10 m/s; corresponding strain rates in the ice specimens were $80-600 \mathrm{~s}^{-1}$. A pair of backed semiconductor strain gages (SS-060-033-1000PB-S1) strategically attached on to the incident and transmitter bars were utilized in combination with a Wheatstone bridge circuit, a differential amplifier (Tektronix $5 A 22 N$ ), and a digital oscilloscope (Tektronix TDS 420) to record the strain pulses in the incident and transmitter bars during the dynamic tests.

In order to enable high rate compression tests on ice at temperatures lower than room temperature, the conventional SHPB was modified to incorporate a cooling chamber around the specimen. Also, a self-pressurized liquid nitrogen tank equipped with a nozzle spray tool was employed to direct a spray of liquid nitrogen directly on the sandwiched ice specimens between the inserts. The temperature of the specimen was monitored by a $0.381 \mathrm{~mm}$ diameter chromel-alumel wire thermocouple secured in a machined screw hole by a matched aluminum bolt in one of the inserts sandwiching the ice specimen. Using this procedure, high a

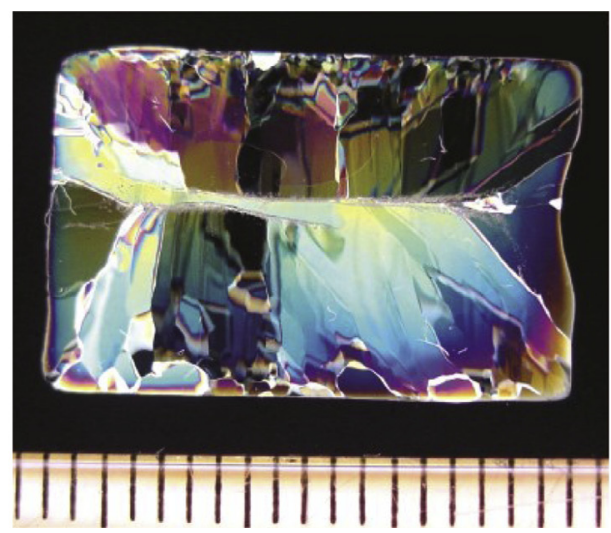

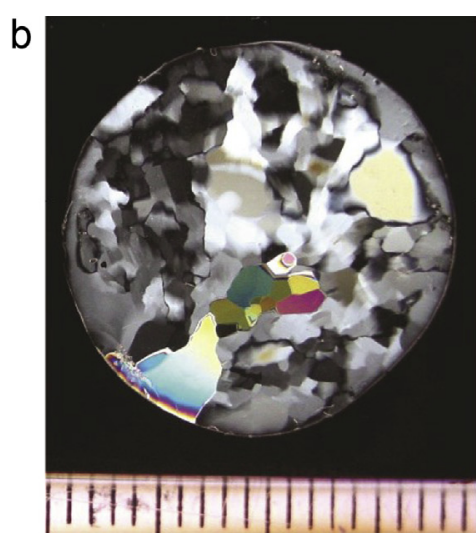

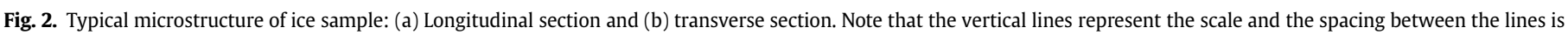
$1 \mathrm{~mm}$. 


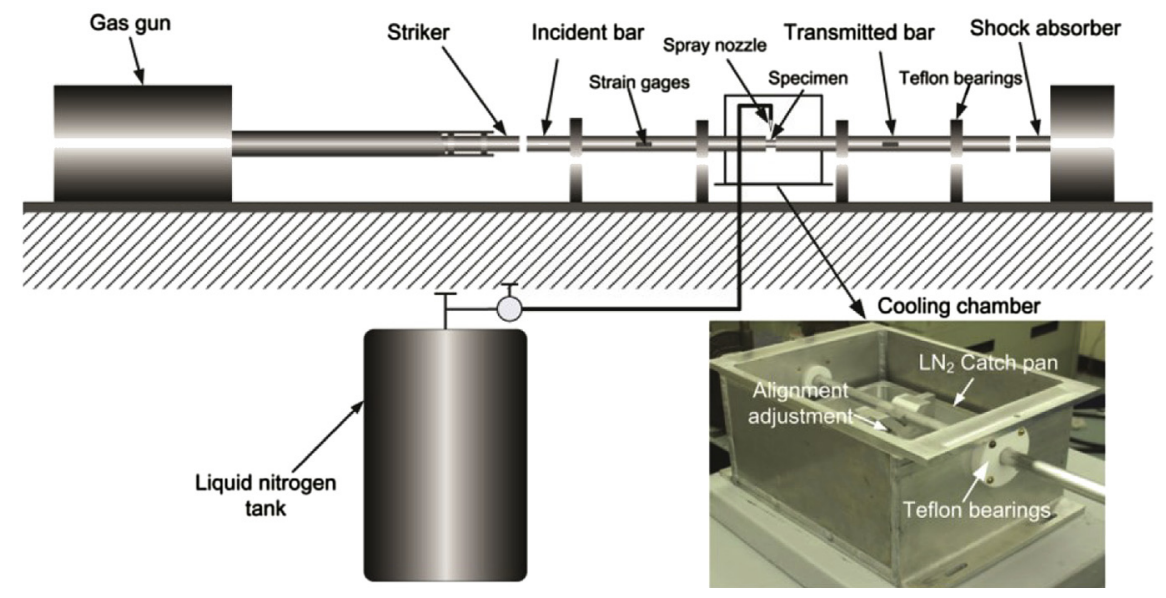

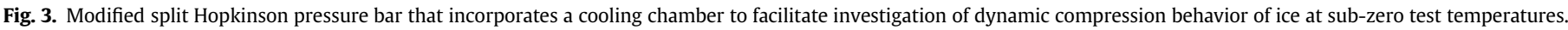

strain rate SHPB dynamic compression tests were conducted on ice at sub-zero temperatures of approximately $-15^{\circ} \mathrm{C}$.

In a typical SHPB test, a compressed air gas-gun is used to accelerate the striker bar to impact the incident bar at a predetermined velocity. The impact results in an elastic compression wave with a strain profile $\varepsilon_{I}(t)$, which travels in the incident bar towards the specimen. Due to the impedance mismatch between the ice specimen and the pressure bars, part of the incident compressive wave is reflected back into the incident bar, denoted by $\varepsilon_{R}(t)$, while the rest, denoted by $\varepsilon_{T}(t)$, is transmitted through the specimen into transmitter bar. Under the assumption of homogeneous deformation, elementary 1D elastic wave-propagation equations are used to calculate the engineering stress $\sigma_{S}(t)$, the strain rate $\dot{\varepsilon}_{S}(t)$, and strain $\varepsilon_{S}(t)$ in the specimen as

$\sigma_{S}(t)=E \frac{A_{0}}{A_{S}} \varepsilon_{T}(t)$

$\dot{\varepsilon}_{S}(t)=-2 \frac{c_{0}}{L_{S}} \varepsilon_{R}(t)$

$\varepsilon_{S}(t)=\int_{0}^{t} \dot{\varepsilon}_{S}(t) \mathrm{d} t$

For the oblique impact Hopkinson bar experiments, the engineering stress $\sigma_{S N}(t)$, the strain rate $\dot{\varepsilon}_{S N}(t)$, and strain $\varepsilon_{S N}(t)$ along the normal (axial) direction are as follows (see Fig. 4),
$\sigma_{S N}(t)=E \frac{A_{0}}{A_{S}} \varepsilon_{T N}(t)=E \frac{A_{0}}{A_{S}} \varepsilon_{T}(t) \cos \theta$

$\dot{\varepsilon}_{S N}(t)=-2 \frac{c_{0}}{L_{S}} \varepsilon_{R N}(t)=-2 \frac{c_{0}}{L_{S}} \varepsilon_{R}(t) \cos \theta$

$\varepsilon_{S N}(t)=\int_{0}^{t} \dot{\varepsilon}_{S N}(t) \mathrm{d} t$

In Eqs. (3)-(8), $E, A_{0}$ and $c_{0}$ are Young's modulus, cross-sectional area, and longitudinal wave speed in the incident and transmitted bars, respectively; $A_{S}$ and $L_{S}$ are the initial cross-sectional area and length of the specimen, respectively; and $\theta$ is the inclined angle as depicted in Fig. 2. Note that for pressure-shear experiments, $A_{S}$ and $L_{S}$ are defined as in Fig. 2.

\subsection{Constant strain-rate experimental method}

Stress equilibrium within specimen is important for SHPB experiments. As pointed out by Davies and Hunter [31], in a typical split Hopkinson bar experiment the stress within the specimen reaches equilibrium state after approximately $\pi$ reverberations of the stress pulse within the specimen.

$t_{\text {equil }}=\frac{\pi L_{0}}{c_{\text {ice }}}$

where, $L_{0}$ is length of specimen and $c_{\text {ice }}$ is longitudinal elastic wave speed in ice. Ice's average Young's modulus is $\sim 10 \mathrm{GPa}$ and its

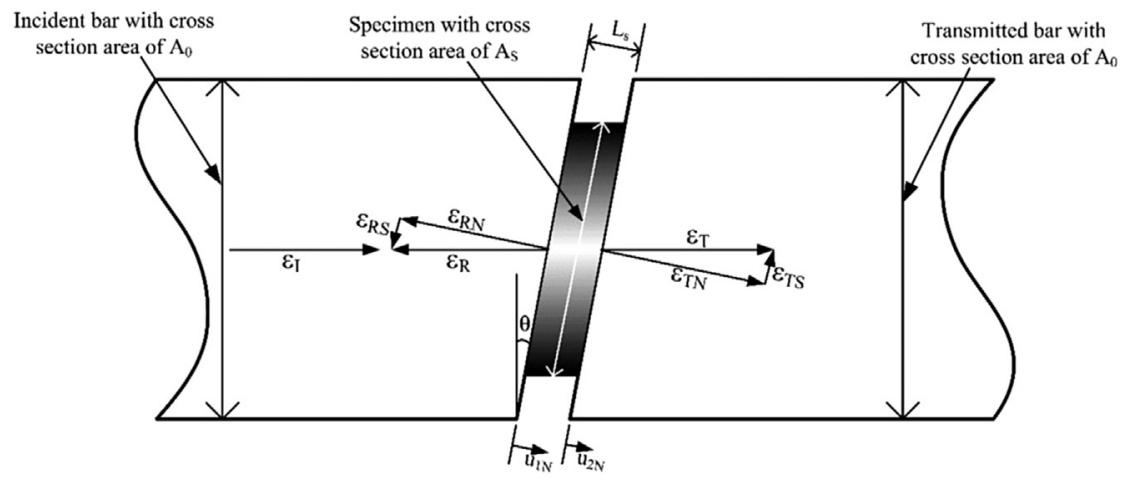

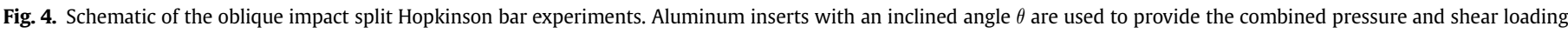
on the ice samples. The strain and particle velocities were decomposed into normal and shear components. 


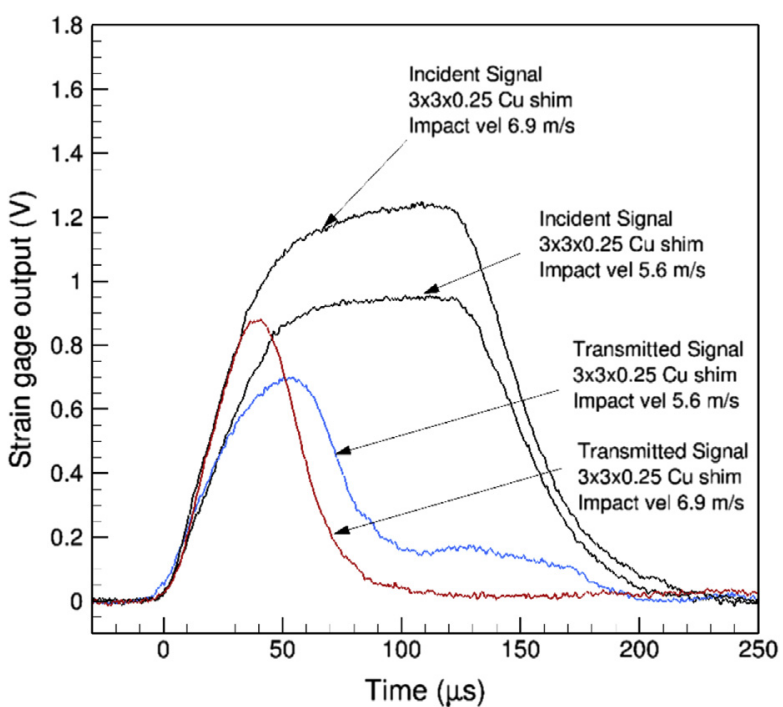

Fig. 5. Pulse shaper optimization by trial and error method to match the slopes of the incident and transmitted signals for impact velocities of 5.6 and $6.9 \mathrm{~m} / \mathrm{s}$.

density is approximate $897 \mathrm{~kg} / \mathrm{m}^{3}$. These values provide an average longitudinal elastic wave speed in ice of about $3338 \mathrm{~m} / \mathrm{s}$. In the present study, the longitudinal elastic wave speed of lake water ice is assumed to be the same as that of distilled water ice. Using Eq. (9), the equilibrium time for a $3 \mathrm{~mm}$ thick ice specimen can be approximated to be $3 \mu \mathrm{s}$. Therefore, the times for the attainment of peak stress in the ice specimens must be greater than those required to reach an equilibrium stress state. This condition can be facilitated using a pulse shaper to increase the rise time of the incident loading pulse. In view of this, in the present study, annealed copper shims of various sizes were used as the pulse shapers for all of the experiments. The copper shims were firmly cemented on the impact end of the incident bar using a thin layer of vacuum grease, and thus get sandwiched between striker and the incident bar during impact. The size of the shim was determined by trial and error depending on the impact velocity and the type of ice being tested [32]. Firstly, a test was run with an arbitrary pulse shaper size. The transmitted signal was then used to optimize the size of pulse shaper by matching the slopes of the incident signals with that of the transmitted signal.

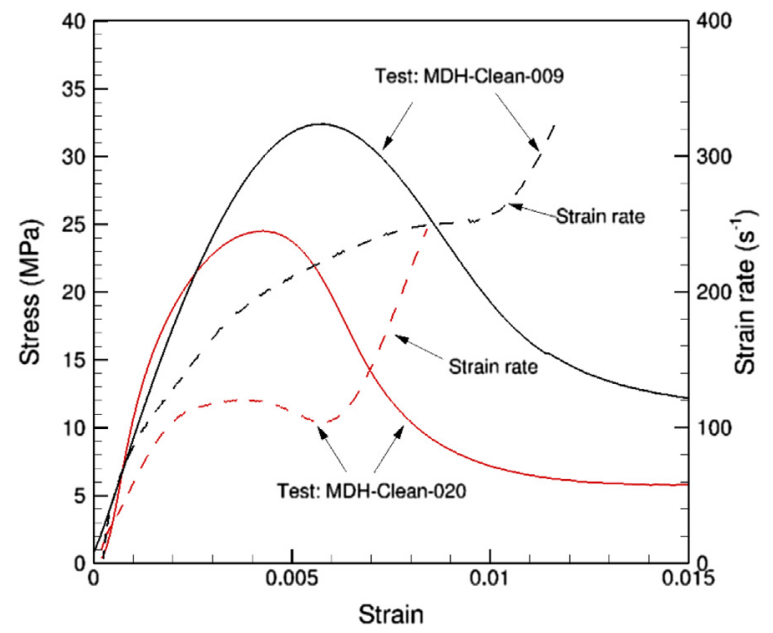

Fig. 6. Stress and strain rate versus strain for two representative experiments of MDHClean-009 and MDH-Clean-020 at a temperature of approximately $-15^{\circ} \mathrm{C}$.
Table 2

Experimental parameters for experiments involving uniaxial compression on distilled water ice specimens.

\begin{tabular}{lllll}
\hline Test name & Test specimen & $\begin{array}{l}\text { Test } \\
\text { temp }\left({ }^{\circ} \mathrm{C}\right)\end{array}$ & $\begin{array}{l}\text { Thickness } \\
(\mathrm{mm})\end{array}$ & $\begin{array}{l}\text { Pulse shaper } \\
(\mathrm{mm})\end{array}$ \\
\hline MDH-Clean-004 & Distilled water ice & -13 & 3.060 & $3 \times 3 \times 0.25$ \\
MDH-Clean-008 & Distilled water ice & -13 & 2.385 & $3 \times 3 \times 0.25$ \\
MDH-Clean-009 & Distilled water ice & -14 & 2.535 & $3 \times 3 \times 0.25$ \\
MDH-Clean-010 & Distilled water ice & -15 & 2.515 & $3 \times 3 \times 0.25$ \\
MDH-Clean-020 & Distilled water ice & -15 & 4.737 & $3 \times 3 \times 0.25$ \\
MDH-Clean-021 & Distilled water ice & -14 & 3.017 & $3 \times 3 \times 0.25$ \\
MDH-Clean-022 & Distilled water ice & -14 & 2.880 & $3 \times 3 \times 0.25$ \\
MDH-Clean-023 & Distilled water ice & -14 & 2.780 & $3 \times 3 \times 0.25$ \\
\hline
\end{tabular}

Fig. 5 shows results of experiments conducted to optimize the size of the pulse shaper at impact velocities of 5.6 and $6.9 \mathrm{~m} / \mathrm{s}$. It is apparent that the slopes of the incident and transmitted pulses obtained using a pulse shaper of size $3 \times 3 \times 0.25 \mathrm{~mm}$ at impact velocities of $5.6 \mathrm{~m} / \mathrm{s}$ and $6.9 \mathrm{~m} / \mathrm{s}$, are quite similar. Consequently, annealed copper pulse shapers of size $3 \times 3 \times 0.25 \mathrm{~mm}$ were used to achieve near constant strain rate loading of the ice specimens during the dynamic compression tests.

As pointed out by Shazly et al. [20], since ice is a brittle material in the range of temperatures and strain rates of interest to the present study, there is little time to establish a constant strain-rate before the samples fail. As shown in Fig. 6 for two representative experiments (MDH-Clean-009 and MDH-Clean-020) the strain rate in the ice samples increased with the loading duration, and a near constant strain rate was achieved near the peak stress using pulse shapers. The sharp increase in strain rate can be attributed to the failure of the ice samples past their peak stress. The strain rates listed in the following tables represent an average value near the peak stress of the stress-strain curves. It is difficult to obtain constant strain rates over the entire duration of loading for the ice samples. Similar challenges have been observed during high strain rate SHPB testing of other brittle materials, such as, Zr-based bulk metallic glass [33,34], ceramics [35] and rocks [36,37] in our research group and also by other groups $[32,38]$.

\section{Experimental results}

\subsection{Results of uniaxial compression tests on distilled water ice}

To understand the difference in the dynamic compressive behavior of lake water ice and distilled water ice, the first series of experiments were conducted on distill water ice that were grown using de-ionized water at temperatures of approximately $-15^{\circ} \mathrm{C}$. Tables 2 and 3 summarize the experimental parameters and some of the key results for all the tests on distilled water ice. The tables provides the information on experimental number, test specimen, test temperature, specimen thickness, pulse shaper size, impact

Table 3

Experimental results for uniaxial compression on distilled water ice specimens.

\begin{tabular}{lllll}
\hline Test name & $\begin{array}{l}\text { Impact } \\
\text { velocity }(\mathrm{m} / \mathrm{s})\end{array}$ & $\begin{array}{l}\text { Peak } \\
\text { stress }(\mathrm{MPa})\end{array}$ & $\begin{array}{l}\text { Strain at peak } \\
\text { stress }\left(\times 10^{-3}\right)\end{array}$ & $\begin{array}{l}\text { Strain } \\
\text { rate }\left(\mathrm{s}^{-1}\right)\end{array}$ \\
\hline MDH-Clean-004 & 5.14 & 26.61 & 7.69 & 119 \\
MDH-Clean-008 & 5.18 & 25.67 & 7.92 & 156 \\
MDH-Clean-009 & 7.04 & 32.40 & 5.85 & 224 \\
MDH-Clean-010 & 7.04 & 33.62 & 7.45 & 272 \\
MDH-Clean-020 & 4.95 & 24.51 & 4.06 & 117 \\
MDH-Clean-021 & 1.89 & 26.84 & 5.33 & 100 \\
MDH-Clean-022 & 2.46 & 28.42 & 4.73 & 118 \\
MDH-Clean-023 & 3.01 & 30.85 & 3.52 & 175 \\
\hline
\end{tabular}




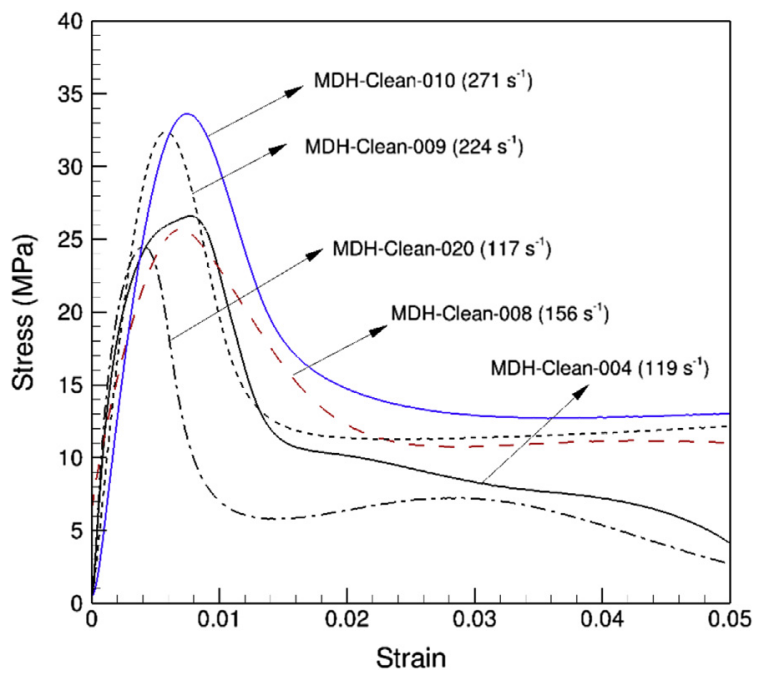

Fig. 7. Stress versus strain profiles for uniaxial compression on distilled water ice grown using aluminum insert at a temperature of approximately $-15^{\circ} \mathrm{C}$.

velocity, peak stress, strain at peak stress, and the average strain rate. For tests MDH-Clean-021, MDH-Clean-022, and MDH-Clean023, a pair of steel inserts of $11.23 \mathrm{~mm}$ in diameter and $31.75 \mathrm{~mm}$ in length were used to grow the ice specimens. The diameters of the steel inserts were selected such that the acoustic impedance of the steel and aluminum inserts was nearly identical. Except for these tests, for all other experiments on distill water and lake water ice, the samples were grown using aluminum inserts $19.05 \mathrm{~mm}$ in diameter and $31.75 \mathrm{~mm}$ in length. The impact velocities of the striker bar were varied from 4.95 to $7.04 \mathrm{~m} / \mathrm{s}$ for experiments conducted using aluminum inserts and $1.89-3.01 \mathrm{~m} / \mathrm{s}$ for the steel inserts; the corresponding strain rates varied from 117 to $272 \mathrm{~s}^{-1}$. The peak stresses in ice were observed to vary from 24.51 MPa to 33.62 $\mathrm{MPa}$, while the strains at the peak stresses were $3.52 \times 10^{-3}$ to $7.92 \times 10^{-3}$.

Figs. 7 and 8 show the stress versus strain curves for tests conducted on distill water ice specimens grown using de-ionized water at a temperature of approximately $-15^{\circ} \mathrm{C}$. All specimens were observed to fail by uniaxial crushing during these tests. Also,

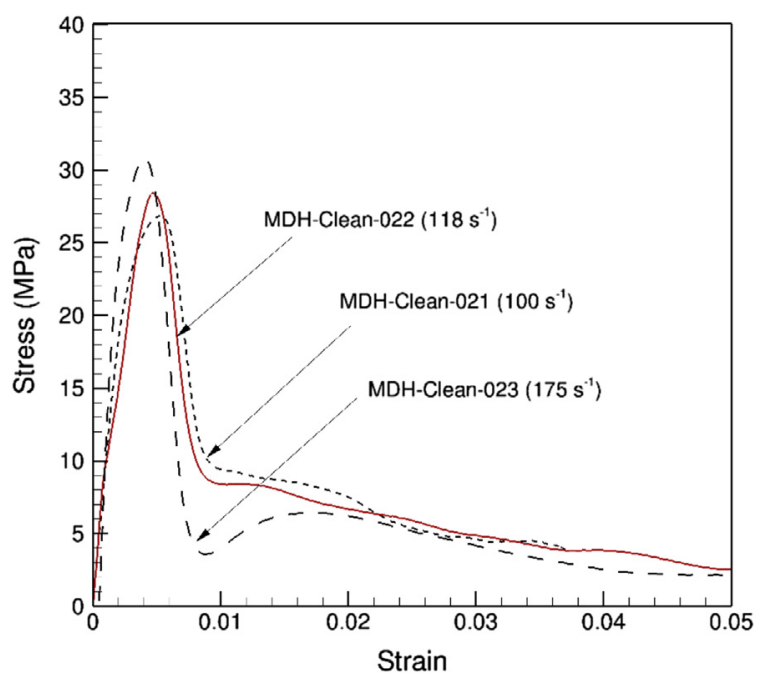

Fig. 8. Stress versus strain profiles for uniaxial compression on distilled water ice grown using steel insert at a temperature of approximately $-15^{\circ} \mathrm{C}$.
Table 4

Experimental parameters for experiments involving uniaxial compression on lake water ice specimens.

\begin{tabular}{lllll}
\hline Name & Test specimen & $\begin{array}{l}\text { Test temp } \\
\left({ }^{\circ} \mathrm{C}\right)\end{array}$ & $\begin{array}{l}\text { Thickness } \\
(\mathrm{mm})\end{array}$ & $\begin{array}{l}\text { Pulse shaper } \\
(\mathrm{mm})\end{array}$ \\
\hline MDH-No1-001 & Lake water ice & -16 & 3.185 & $3 \times 3 \times 0.25$ \\
MDH-No1-002 & Lake water ice & -17 & 2.954 & $3 \times 3 \times 0.25$ \\
MDH-No1-003 & Lake water ice & -17 & 3.235 & $3 \times 3 \times 0.25$ \\
MDH-No1-004 & Lake water ice & -17 & 3.200 & $3 \times 3 \times 0.25$ \\
MDH-No1-005 & Lake water ice & -16 & 2.885 & $3 \times 3 \times 0.25$ \\
MDH-No1-007 & Lake water ice & -15 & 3.252 & $3 \times 3 \times 0.25$ \\
MDH-No1-008 & Lake water ice & -17 & 3.381 & $3 \times 3 \times 0.25$ \\
MDH-No1-009 & Lake water ice & -17 & 3.194 & $4 \times 4 \times 0.25$ \\
MDH-No1-010 & Lake water ice & -15 & 3.388 & $3 \times 3 \times 0.25$ \\
MDH-No1-013 & Lake water ice & -15 & 3.283 & $3 \times 3 \times 0.25$ \\
MDH-No1-014 & Lake water ice & -15 & 3.047 & $3 \times 3 \times 0.25$ \\
\hline
\end{tabular}

the peak stresses are observed to increase with increasing strain rates. It is interesting to note that the dynamic stress versus strain profiles for distill water ice do not show a catastrophic drop in load carrying capacity after the attainment of the peak (failure) stress. The residual compressive strengths for ice in these tests are maintained at a level as high as $13 \mathrm{MPa}$ for tests MDH-Clean-008, MDH-Clean-009 and MDH-Clean-010, as shown in Figs. 7 and 8. The average strain at the attainment of peak stress for this series of tests was measured to be $5.85 \pm 2.33 \times 10^{-3}$.

\subsection{Results of uniaxial compression tests on lake water ice}

Next, the dynamic compressive behavior of lake water ice was investigated at various strain rates and a temperature of approximately $-15^{\circ} \mathrm{C}$. The chemical composition of the lake water (dirty) ice is given in Table 1 . The experimental parameters for this set of experiments are summarized in Table 4, while the experimental results are summarized in Table 5. The impact velocities of the striker bar varied from 4.30 to $10.39 \mathrm{~m} / \mathrm{s}$ and the corresponding strain rates varied from 116 to $243 \mathrm{~s}^{-1}$. The peak stresses in the lake water ice were observed to vary from 26.76 to $41.25 \mathrm{MPa}$. It is interesting to note that the peak stresses in lake water ice are almost 22\% higher than that obtained for distilled water ice at essentially the same range of strain rates and test temperatures. The strains at the peak stresses were observed to vary from $2.54 \times 10^{-3}$ to $10.10 \times 10^{-3}$.

The stress versus strain curves for the tests conducted on lake water ice specimens are shown in Figs. 9-11. In all experiments the specimens were observed to fail during the dynamic loading except for test MDH-No1-001, which deformed nearly elastically as evident from the elastic unloading curve. Also, the slope of the

Table 5

Experimental results for experiments involving uniaxial compression on lake water ice specimens.

\begin{tabular}{lclll}
\hline Test name & $\begin{array}{l}\text { Impact } \\
\text { velocity }(\mathrm{m} / \mathrm{s})\end{array}$ & $\begin{array}{l}\text { Peak stress } \\
(\mathrm{MPa})\end{array}$ & $\begin{array}{l}\text { Strain at peak } \\
\text { stress }\left(\times 10^{-3}\right)\end{array}$ & $\begin{array}{l}\text { Strain rate } \\
\left(\mathrm{s}^{-1}\right)\end{array}$ \\
\hline MDH-No1-001 & 4.30 & 26.76 & 4.44 & 141 \\
MDH-No1-002 & 6.99 & 40.75 & 5.57 & 263 \\
MDH-No1-003 & 6.93 & 36.35 & 7.40 & 208 \\
MDH-No1-004 & 5.49 & 32.30 & 8.24 & 156 \\
MDH-No1-005 & 6.09 & 35.04 & 7.01 & 190 \\
MDH-No1-007 & 8.54 & 40.59 & 3.08 & 172 \\
MDH-No1-008 & 8.82 & 43.78 & 4.59 & 243 \\
MDH-No1-009 & 10.39 & 41.25 & 2.54 & 212 \\
MDH-No1-010 & 5.25 & 31.04 & 8.49 & 108 \\
MDH-No1-013 & 6.18 & 34.20 & 8.10 & 191 \\
MDH-No1-014 & 6.45 & 34.09 & 6.04 & 223 \\
\hline
\end{tabular}




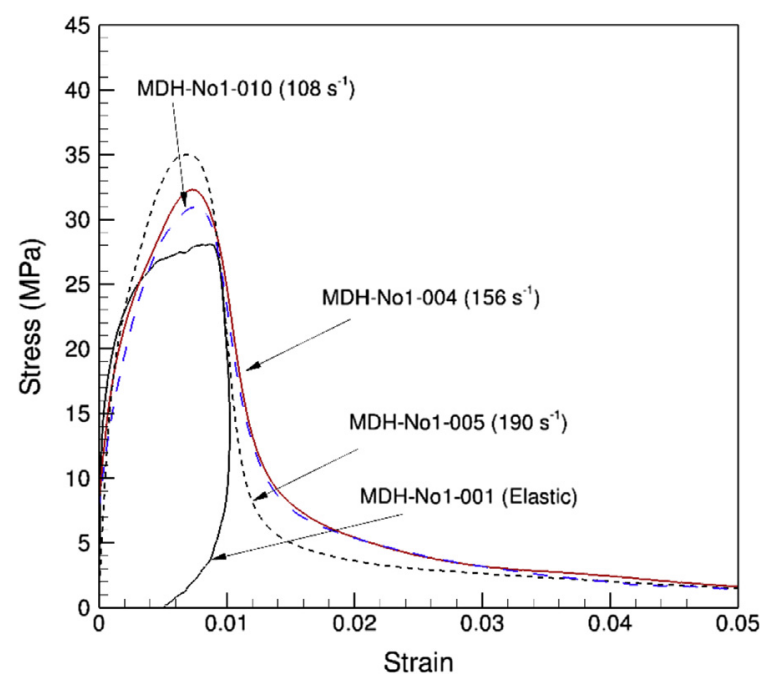

Fig. 9. Stress versus strain profiles for uniaxial compression on lake water ice at impact velocities of striker range $4.30-6.09 \mathrm{~m} / \mathrm{s}$ at a temperature of approximately $-15^{\circ} \mathrm{C}$.

stress versus strain curve obtained before the attainment of the peak stress in test MDH-No1-010 was a than the other curves. This may be ascribed to a few small air bubbles left behind in the ice specimens during ice growth and specimen preparation. The peak stresses were observed to increase with increasing strain rates except for test MDH-No1-014. It is interesting to note that the peak stresses obtained for lake water ice are a little higher than obtained from the distilled water ice specimens. Also, the stress versus strain curves for lake water ice specimens show residual strength after the attainment of the peak stress. However, the residual strength levels are approximately $5 \mathrm{MPa}$, which are much lower than that measured for distilled water ice specimens. Additionally, the residual strength for lake water ice continues to decrease with increasing strains during the duration of the experiment. The average strain at peak stress for this test series is $6.30 \pm 3.78 \times 10^{-3}$, which is a little higher when compared to the average strain measured for the distilled water ice.

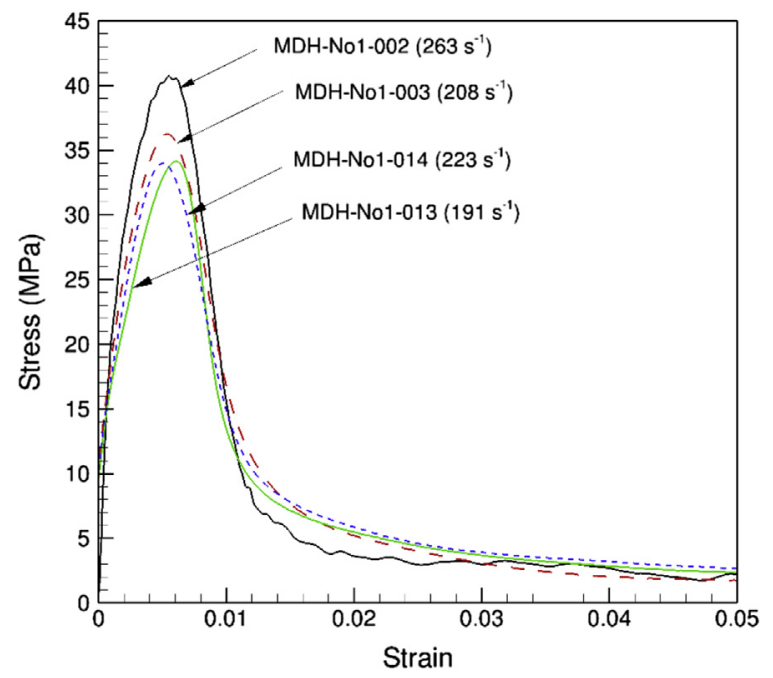

Fig. 10. Stress versus strain profiles for uniaxial compression on lake water ice at impact velocities of striker range $6.18-6.99 \mathrm{~m} / \mathrm{s}$ at a temperature of approximately $-15^{\circ} \mathrm{C}$.

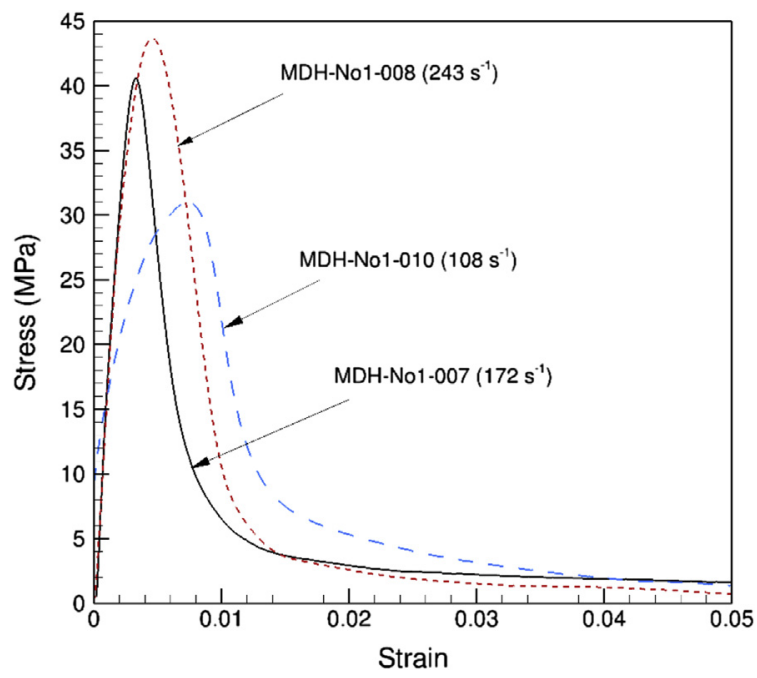

Fig. 11. Stress versus strain profiles for uniaxial compression on lake water ice at highest impact velocities of striker at a temperature of approximately $-15^{\circ} \mathrm{C}$.

\subsection{Results of oblique impact tests on lake water ice}

The oblique impact experiments were conducted to investigate the effects of combined compression and shear loading on dynamic behavior of ice at high loading rate. For these experiments the ice specimens were harvested using $20^{\circ}$ inclined aluminum inserts. The experiments were conducted at a temperature of approximately $-15^{\circ} \mathrm{C}$. Tables 6 and 7 summarize the experimental parameters and results, respectively, for the oblique impact tests on the lake water ice specimens. The impact velocity of the striker bar was varied from 4.41 to $8.36 \mathrm{~m} / \mathrm{s}$, and the corresponding strain rates were in the range $245-591 \mathrm{~s}^{-1}$, which were consistently higher than those obtained under uniaxial compression loading at the same impact velocity range. The peak stresses were observed to vary from 9.25 MPa (test INCL-No1-023) to 24.86 MPa (test INCLNo1-005), which were lower than those obtained under normal impact loading for lake water ice. The strains at the peak stress were observed to vary from $3.15 \times 10^{-3}$ for test INCL-No1-023 to $14.0 \times 10^{-3}$ for test INCL-No1-002.

Table 6

Experimental parameters for experiments oblique impact on lake water ice specimens.

\begin{tabular}{lllll}
\hline Test name & Test specimen & $\begin{array}{l}\text { Test } \\
\text { temperature } \\
\left({ }^{\circ} \mathrm{C}\right)\end{array}$ & $\begin{array}{l}\text { Thickness } \\
(\mathrm{mm})\end{array}$ & $\begin{array}{l}\text { Pulse shaper } \\
(\mathrm{mm})\end{array}$ \\
\hline INCL-No1-001 & Lake water ice & -15 & 3.218 & $3 \times 3 \times 0.25$ \\
INCL-No1-002 & Lake water ice & -15 & 3.285 & $3 \times 3 \times 0.25$ \\
INCL-No1-003 & Lake water ice & -16 & 3.450 & $3 \times 3 \times 0.25$ \\
INCL-No1-004 & Lake water ice & -15 & 3.140 & $3 \times 3 \times 0.25$ \\
INCL-No1-005 & Lake water ice & -15 & 3.107 & $3 \times 3 \times 0.25$ \\
INCL-No1-006 & Lake water ice & -14 & 3.422 & $3 \times 3 \times 0.25$ \\
INCL-No1-007 & Lake water ice & -15 & 3.389 & $3 \times 3 \times 0.25$ \\
INCL-No1-008 & Lake water ice & -15 & 3.167 & $3 \times 3 \times 0.25$ \\
INCL-No1-010 & Lake water ice & -15 & 3.183 & $3 \times 3 \times 0.25$ \\
INCL-No1-011 & Lake water ice & -15 & 3.436 & $3 \times 3 \times 0.25$ \\
INCL-No1-012 & Lake water ice & -15 & 3.346 & $3 \times 3 \times 0.25$ \\
INCL-No1-013 & Lake water ice & -15 & 3.210 & $3 \times 3 \times 0.25$ \\
INCL-No1-014 & Lake water ice & -15 & 3.562 & $3 \times 3 \times 0.25$ \\
INCL-No1-015 & Lake water ice & -15 & 3.295 & $3 \times 3 \times 0.25$ \\
INCL-No1-016 & Lake water ice & -13 & 3.384 & $3 \times 3 \times 0.25$ \\
INCL-No1-018 & Lake water ice & -12 & 3.582 & $3 \times 3 \times 0.25$ \\
INCL-No1-019 & Lake water ice & -15 & 3.608 & $3 \times 3 \times 0.25$ \\
INCL-No1-023 & Lake water ice & -15 & 3.272 & $3 \times 3 \times 0.25$ \\
INCL-No1-026 & Lake water ice & -15 & 3.205 & $3 \times 3 \times 0.25$ \\
\hline
\end{tabular}


Table 7

Experimental results for oblique impact on lake water ice specimens.

\begin{tabular}{llccl}
\hline Test name & $\begin{array}{l}\text { Impact } \\
\text { velocity }(\mathrm{m} / \mathrm{s})\end{array}$ & $\begin{array}{l}\text { Peak stress } \\
(\mathrm{MPa})\end{array}$ & $\begin{array}{l}\text { Strain at peak } \\
\text { stress }\left(\times 10^{-3}\right)\end{array}$ & $\begin{array}{l}\text { Strain rate } \\
\left(\mathrm{s}^{-1}\right)\end{array}$ \\
\hline INCL-No1-001 & 5.42 & 17.39 & 6.90 & 463 \\
INCL-No1-002 & 5.13 & 16.46 & 14.00 & 570 \\
INCL-No1-003 & 5.56 & 17.82 & 7.34 & 428 \\
INCL-No1-004 & 5.77 & 17.75 & 8.36 & 505 \\
INCL-No1-005 & 7.04 & 24.86 & 6.04 & 430 \\
INCL-No1-006 & 6.44 & 22.46 & 3.44 & 245 \\
INCL-No1-007 & 5.08 & 12.74 & 9.20 & 501 \\
INCL-No1-008 & 5.37 & 13.94 & 5.44 & 379 \\
INCL-No1-010 & 6.46 & 16.61 & 6.33 & 407 \\
INCL-No1-011 & 6.99 & 18.79 & 5.21 & 346 \\
INCL-No1-012 & 7.48 & 19.70 & 8.26 & 591 \\
INCL-No1-013 & 7.34 & 18.72 & 5.64 & 412 \\
INCL-No1-014 & 8.36 & 21.11 & 4.74 & 368 \\
INCL-No1-015 & 4.72 & 9.95 & 6.75 & 299 \\
INCL-No1-016 & 5.80 & 11.97 & 8.33 & 430 \\
INCL-No1-018 & 7.03 & 13.97 & 6.85 & 357 \\
INCL-No1-019 & 6.99 & 13.09 & 8.37 & 453 \\
INCL-No1-023 & 4.56 & 9.25 & 3.15 & 190 \\
INCL-No1-026 & 4.41 & 9.58 & 7.20 & 349 \\
\hline
\end{tabular}

Figs. 12 and 13 show the stress versus strain curves obtained for the oblique impact experiments at different strain rates and at a temperature of approximately $-15{ }^{\circ} \mathrm{C}$. It is interesting to note that the shapes of the stress-strain curves obtained for the oblique impact experiments on lake water ice are quite different when compared to those obtained from uniaxial impact experiments. The strains at the peak stress are larger and the stresses unload slower with strain when compared to the uniaxial compression experiments. The total inelastic strain before ice specimen loses all its stress carrying capacity during the experiment is as large as 0.15 . The average strain for this series of tests was $7.06 \pm 6.95 \times 10^{-3}$, which is also much higher than obtained from the uniaxial impact tests. Moreover, in view of all the results from these tests the peak stresses are observed to increase consistently with increasing strain rates.

\subsection{Results of oblique tests on distilled water ice}

Like for the case of lake water ice experiments, the oblique impact tests on distilled water ice specimens were conducted at a

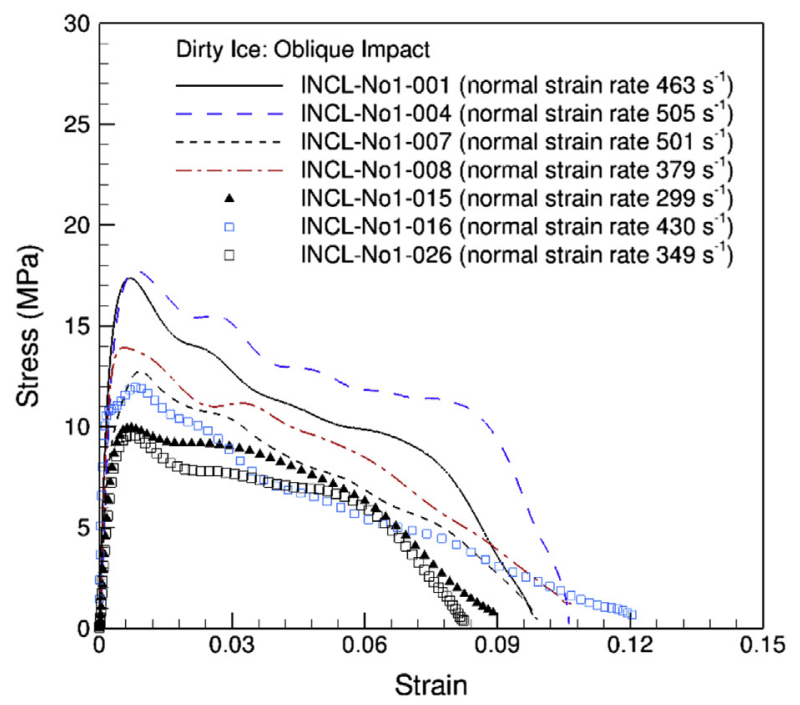

Fig. 12. Stress versus strain profiles for $20^{\circ}$ oblique impact experiments on lake water ice at impact velocities of striker range $4.41-5.80 \mathrm{~m} / \mathrm{s}$ at a temperature of approximately $-15^{\circ} \mathrm{C}$.

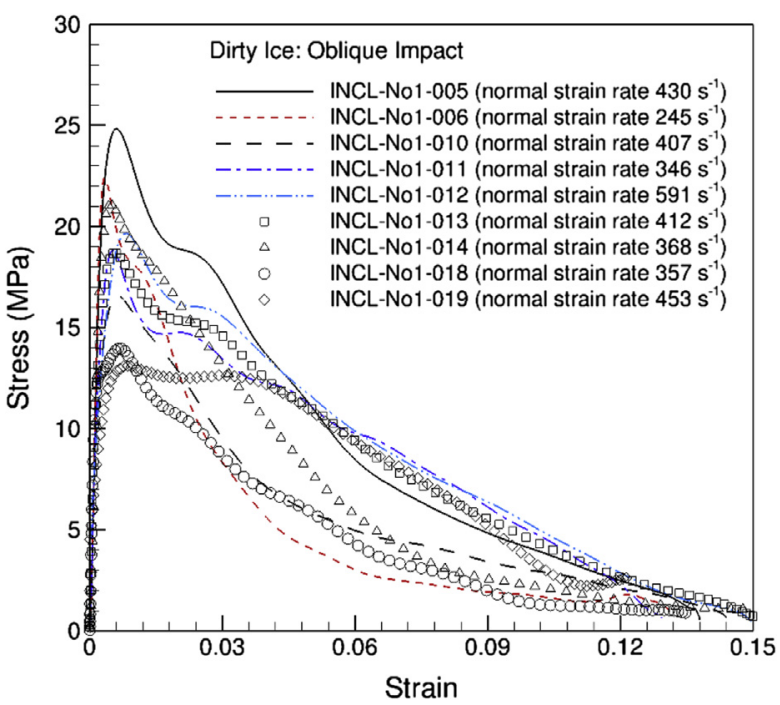

Fig. 13. Stress versus strain profiles for $20^{\circ}$ oblique impact experiments on lake water ice at impact velocities of striker range $6.44-8.36 \mathrm{~m} / \mathrm{s}$ at a temperature of approximately $-15{ }^{\circ} \mathrm{C}$.

test temperature of approximately $-15{ }^{\circ} \mathrm{C}$. Tables 8 and 9 summarize the experimental parameters and the test results, respectively. The impact velocities of the striker bar varied from $3.28 \mathrm{~m} / \mathrm{s}$ for the test INCL-Clean-003 to $6.93 \mathrm{~m} / \mathrm{s}$ for test INCL-Clean-005, and the corresponding strain rates varied from 270 to $574 \mathrm{~s}^{-1}$, which were higher than those obtained for the uniaxial compression tests on distilled water ice in the same impact velocity range. Moreover the peak stresses were observed to vary from $8.12 \mathrm{MPa}$ for test INCL-Clean-003 to $16.54 \mathrm{MPa}$ for the test INCL-Clean-006, which were much lower than those obtained for the uniaxial compression loading tests. The strains corresponding to the peak stress were observed to vary from $3.55 \times 10^{-3}$ for test INCL-Clean-012 to $10.6 \times 10^{-3}$ for the test INCL-Clean-005.

Figs. 14 and 15 show the longitudinal stress versus strain profiles obtained from the oblique impact experiments at various longitudinal strain rates for the distilled water ice specimens. Also, the shapes of the longitudinal stress-strain curves obtained from the oblique impact tests on distill water ice are quite different when compared with those obtained from the uniaxial compression impact loading tests. In addition, as also observed for the case of the lake water ice experiments, after failure slow unloading is observed during the oblique impact tests on distilled water ice. Again, the total strain accumulated in the specimens before they completely

Table 8

Experimental parameters for experiments involving oblique impact on distilled water ice specimens.

\begin{tabular}{lllll}
\hline Test name & Test specimen & $\begin{array}{l}\text { Test temp } \\
\left({ }^{\circ} \mathrm{C}\right)\end{array}$ & $\begin{array}{l}\text { Thickness } \\
(\mathrm{mm})\end{array}$ & $\begin{array}{l}\text { Pulse shaper } \\
(\mathrm{mm})\end{array}$ \\
\hline INCL-Clean-001 & Distilled water ice & -15 & 2.472 & $3 \times 3 \times 0.25$ \\
INCL-Clean-002 & Distilled water ice & -15 & 3.293 & $3 \times 3 \times 0.25$ \\
INCL-Clean-003 & Distilled water ice & -15 & 2.858 & $3 \times 3 \times 0.25$ \\
INCL-Clean-004 & Distilled water ice & -15 & 3.314 & $3 \times 3 \times 0.25$ \\
INCL-Clean-005 & Distilled water ice & -14 & 3.064 & $3 \times 3 \times 0.25$ \\
INCL-Clean-006 & Distilled water ice & -15 & 3.405 & $3 \times 3 \times 0.25$ \\
INCL-Clean-007 & Distilled water ice & -15 & 3.033 & $3 \times 3 \times 0.25$ \\
INCL-Clean-008 & Distilled water ice & -15 & 3.204 & $3 \times 3 \times 0.25$ \\
INCL-Clean-010 & Distilled water ice & -15 & 3.234 & $3 \times 3 \times 0.25$ \\
INCL-Clean-011 & Distilled water ice & -15 & 3.245 & $3 \times 3 \times 0.25$ \\
INCL-Clean-012 & Distilled water ice & -15 & 3.425 & $3 \times 3 \times 0.25$ \\
INCL-Clean-013 & Distilled water ice & -15 & 3.097 & $3 \times 3 \times 0.25$ \\
\hline
\end{tabular}


Table 9

Experimental results for oblique impact on distilled water ice specimens.

\begin{tabular}{llccl}
\hline Test name & $\begin{array}{l}\text { Impact } \\
\text { velocity }(\mathrm{m} / \mathrm{s})\end{array}$ & $\begin{array}{l}\text { Peak stress } \\
(\mathrm{MPa})\end{array}$ & $\begin{array}{l}\text { Strain at peak } \\
\text { stress }\left(\times 10^{-3}\right)\end{array}$ & $\begin{array}{l}\text { Strain rate } \\
\left(\mathrm{s}^{-1}\right)\end{array}$ \\
\hline INCL-Clean-001 & 4.23 & 11.42 & 5.90 & 310 \\
INCL-Clean-002 & 4.64 & 10.46 & 7.07 & 337 \\
INCL-Clean-003 & 3.28 & 8.12 & 7.00 & 305 \\
INCL-Clean-004 & 5.91 & 13.02 & 4.94 & 299 \\
INCL-Clean-005 & 6.93 & 14.22 & 10.60 & 574 \\
INCL-Clean-006 & 7.27 & 16.54 & 5.18 & 380 \\
INCL-Clean-007 & 5.48 & 9.42 & 4.31 & 320 \\
INCL-Clean-008 & 6.69 & 17.72 & 3.70 & 301 \\
INCL-Clean-010 & 5.25 & 12.83 & 4.70 & 311 \\
INCL-Clean-011 & 4.90 & 10.62 & 4.74 & 270 \\
INCL-Clean-012 & 6.33 & 9.43 & 3.55 & 281 \\
INCL-Clean-013 & 5.08 & 13.41 & 5.02 & 287 \\
\hline
\end{tabular}

lose their stress carrying capacity is large as 0.15 . The average strain for this series tests was $5.56 \pm 5.08 \times 10^{-3}$, which is also much higher than obtained from the uniaxial impact experiments. Moreover, the peak stresses are observed to increase with increasing strain rates.

\section{Summary of results and discussion}

In the present study the compressive behavior of lake water ice and distill water ice were investigated at high strain rates and a temperature of approximately $-15{ }^{\circ} \mathrm{C}$ using a modified SHPB. Additionally, the effects of shear stress on the compressive behavior of ice were investigated using oblique impact tests. The results of the uniaxial compression tests and the combined compression and shear tests at high loading rates on distill water ice and the lake water ice are compared in Fig. 16. It is observed that the residual strength following peak stress in distill water ice is much higher when compared to that obtained for lake water ice. Also, the stress-strain curves for the oblique impact experiments on lake water ice and distill water ice are much wider when compared with those obtained for the ice specimens under uniaxial compression loading. These differences can be ascribed to the effects of shear stress during the oblique impact tests, where the presence of shear can lead to sliding of the specimens at the specimen/bar interface. In this regards, studies by Kennedy [39] have shown that the

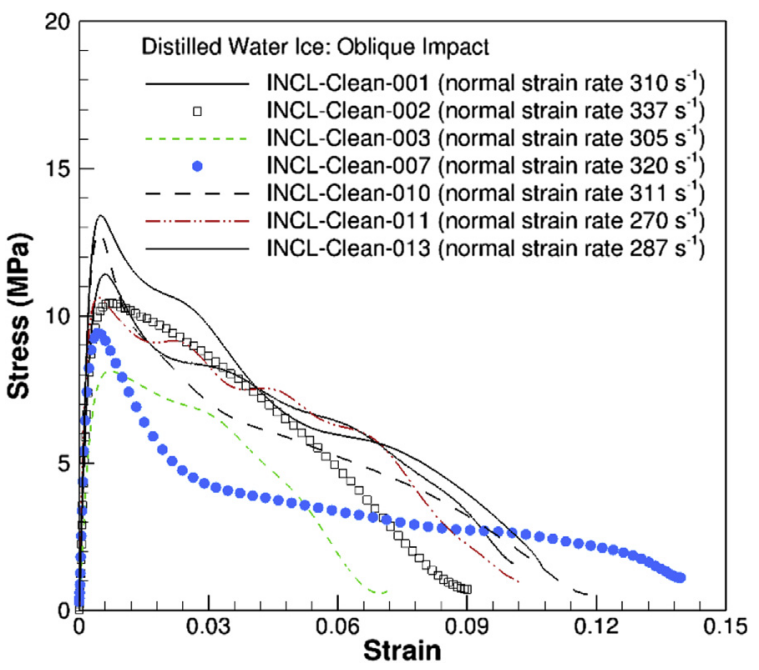

Fig. 14. Stress versus strain profiles for oblique impact experiments on distilled water ice at impact velocities of striker range $3.28-5.48 \mathrm{~m} / \mathrm{s}$ at a temperature of approximately $-15^{\circ} \mathrm{C}$.

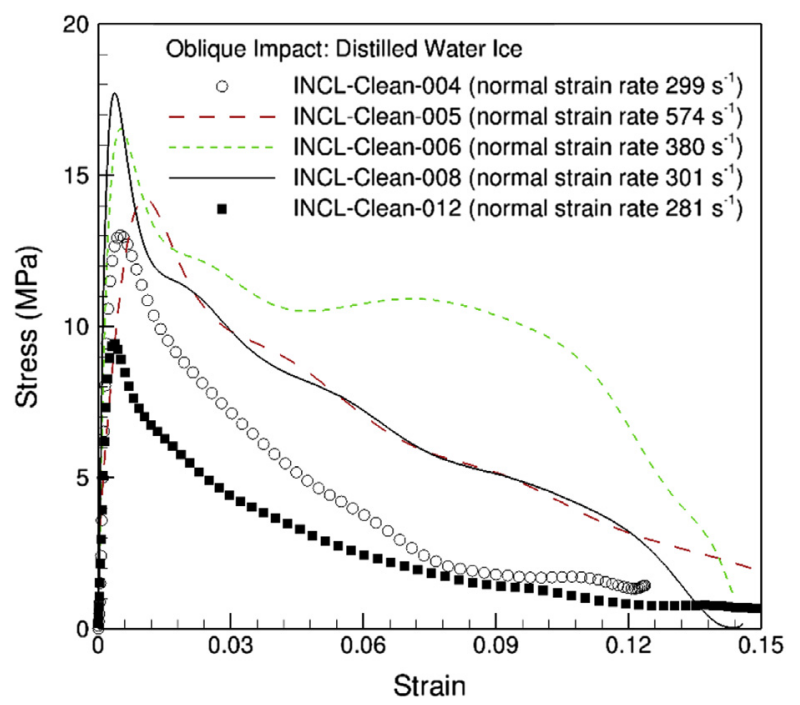

Fig. 15. Stress versus strain profiles for oblique impact experiments on distilled water ice at impact velocities of striker range $5.91-7.27 \mathrm{~m} / \mathrm{s}$ at a temperature of approximately $-15^{\circ} \mathrm{C}$.

friction coefficient of ice on ice at a temperature of $-10^{\circ} \mathrm{C}$ is as high as 0.4 at low sliding speeds, but decreases quickly to lower than 0.1 with an increase of sliding speed. Additionally, studies on the frictional behavior of ice against various materials [39-41] have shown that the coefficient of kinetic friction is reduced by a factor of 10 as the sliding velocity increases from $10^{-5}$ to $0.1 \mathrm{~m} / \mathrm{s}$. In view if this, in the present study, the surfaces of the inserts utilized to grow ice were suitably roughened to prevent sliding of samples at the bar-specimen interface. The peak stresses obtained under oblique impact loading conditions were consistently lower than those obtained under uniaxial impact loading conditions (Fig. 16). Also, it is interesting to note that the peak stress of the lake water ice specimens is consistently higher than those obtained for the distill water ice specimens.

In Fig. 17(a), data from uniaxial compression tests on distill water ice specimens obtained at various strain rates are also shown in the plot. The results of Jones et al. [18], Schulson et al. [7] and

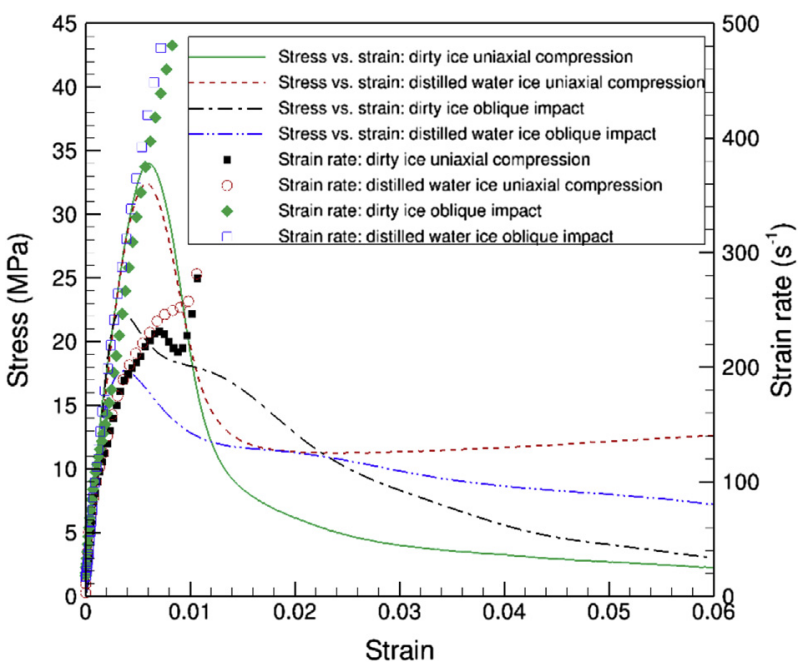

Fig. 16. Typical stress versus strain profiles for normal impact on distilled water ice, normal impact on lake water ice, and $20^{\circ}$ oblique impact on lake water ice and distilled water ice at a temperature of approximately $-15^{\circ} \mathrm{C}$. 

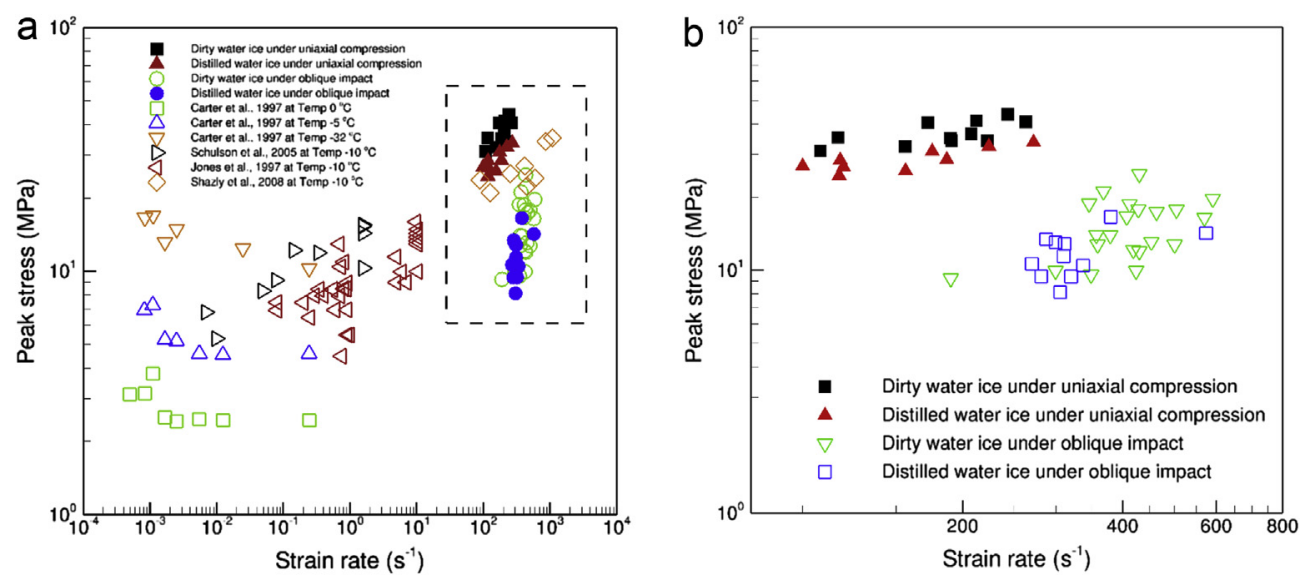

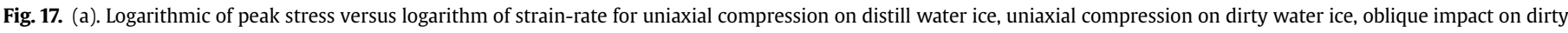

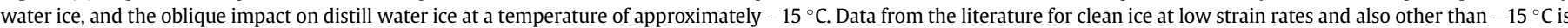

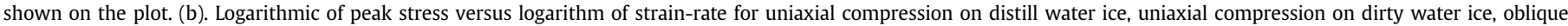
impact on dirty water ice, and the oblique impact on distill water ice at a temperature of approximately $-15^{\circ} \mathrm{C}$.

Shazly et al. $[19,20]$ are consistent with the results obtained in the present study and show similar positive rate effects over the strain rate range of $10^{-2}$ to $10^{3} \mathrm{~s}^{-1}$. It is to be noted that the stress versus strain rate data obtained from the present study have almost the same slopes as the results obtained by Shazly et al. [19,20] on distill water ice at approximately $-10{ }^{\circ} \mathrm{C}$, except that the peak stresses obtained in the present study are a little higher than those reported in the studies by Shazly et al. [19,20].

Fig. 17(b) shows the summary of the logarithmic of peak stress as a function of logarithmic of strain rate obtained under dynamic compression for uniaxial compression on distilled water ice, uniaxial compression on lake water ice, oblique impact on lake water ice, and the oblique impact on distill water ice obtained in the present study at a test temperature of approximately $-15^{\circ} \mathrm{C}$. From the figure it can be seen that the peak stress for both distill water ice and lake water ice under uniaxial compression loading increases with increasing strain rates in the strain rate regime of $80-600 \mathrm{~s}^{-1}$. The peak strengths of the lake water ice specimens are consistently higher than that of the distill water ice specimens. However, the peak stresses obtained from the oblique impact ice specimens are consistently lower than that obtained from uniaxial impact specimens. Also, the sensitivity of logarithmic of strain rate on the logarithmic of peak stress for oblique impact on lake water ice specimens and the oblique impact on distill water ice specimens are much higher when compared to those obtained under uniaxial impact conditions. The dependence of peak stress on strain rate for uniaxial compression of distill water ice and lake water ice, and for distill and lake water ice under oblique impact can be described by the relationships $\sigma=7.196 \dot{\varepsilon}^{0.267}$ with a correlation coefficient of $r^{2}=0.805, \sigma=9.113 \dot{\varepsilon}^{0.267}$ with a correlation coefficient of $r^{2}=0.357$, and $\sigma=0.0756 \dot{\varepsilon}^{0.875}$ with a correlation coefficient of $r^{2}=0.221$, respectively.

The slightly higher strength for lake water ice specimens when compared to the distill water ice can be understood by considering lake water ice as a particle reinforced composite. Also, since the failure of the ice specimens is understood to occur by the initiation and coalescence of wing cracks at the ice grain boundaries, the increase in peak stress for lake water ice when compared to the distilled water ice is perhaps due to pinning and/or deflection of microcracks by the foreign particles. It is also possible that the presence of foreign particulates in lake water ice changes the nucleation and growth mechanisms of ice crystals, thus resulting in smaller grain sizes of higher strength in the ice microstructure. However, previous researches on creep strength have shown that hard particulates of the order of a small volume fraction and of larger size (a few hundred micrometers) have been found to actually weaken ice [22-24]. Whether or not the hard particulates can influence the dynamic compressive strength of lake water ice will be investigated in more detail in the near future.

Unlike most brittle materials, the dynamic stress versus strain profiles for both the lake water ice as well as distill water ice studied in the present investigation under uniaxial compression and oblique impact loading, do not show a catastrophic drop in stress carrying capacity after the attainment of the peak stress. In fact, the peak stress in the samples is followed by a long tail indicating complex inter-particle interactions which lead to non-zero residual strength in the pulverized/fragmented ice. This residual strength of pulverized ice can be best understood by considering the damaged/fragmented ice as an assemblage of wet highlyfragmented granular material, created by adiabatic heating due to grain-to-grain frictional sliding and/or impact-induced melting and recrystallization of molten layer held together by ice melt in the post-peak-stress regime. In addition, the residual strength of lake water ice is observed to be much lower than distill water ice, which could also be ascribed to the difference in microstructures of lake water ice induced by foreign particulates when compared to distill water ice. Since the grain sizes of lake water ice specimens are expected to be smaller when compared to that of distill water ice (because of the presence of foreign particulates), it is possible the dirty ice specimens be crushed into relatively smaller ice fragments when compared to distilled water ice leading to a larger surface area, and hence to greater frictional heating when compared to distill water ice. Consequently, it is highly unlikely that the highlyfragmented granular ice will stay together through recrystallization of the molten ice layer between the fragmented ice grains, which results in a relative lower residual strength for lake water ice.

\section{Acknowledgments}

The authors acknowledge financial support from Hankook Tire Company and NASA under contract NNX13A74A in conducting this research. Also, the authors would like to thank Dr. Jan Terziyski of Hankook Tire Company for several helpful discussions during the course of this research. 


\section{References}

[1] Haynes FD. Effect of temperature on the strength of snow-ice, CRREL-78-27. Hanover, NH: Cold Regions Research and Engineering Laboratory, Corps of Engineering; 1978. p. 1-28.

[2] Currier JH, Schulson EM. The tensile-strength of ice as a function of grain-size. Acta Metall 1982;30:1511-4.

[3] Dempsey JP, Defranco SJ, Adamson RM, Mulmule SV. Scale effects on the insitu tensile strength and fracture of ice. Part I: large grained freshwater ice at Spray Lakes Reservoir, Alberta. Int J Fract 1999;95:325-45.

[4] Dempsey JP, Adamson RM, Mulmule SV. Scale effects on the in-situ tensile strength and fracture of ice. Part II: first-year sea ice at Resolute, NWT. Int J Fract 1999;95:347-66.

[5] Schulson EM. The structure and mechanical behavior of ice. J Miner Metals Mater Soc 1999;51:21-7.

[6] Schulson EM. Brittle failure of ice. Eng Fract Mech 2001;68:1839-87.

[7] Schulson EM, Iliescu D, Fortt A. Characterization of ice for return-to flight of the space shuttle: part I-hard ice. 2005. NASA Contractor Report, 213643. Cleveland, OH: NASA Glenn Research Center.

[8] Nixon WA, Schulson EM. A micromechanical view of the fracture-toughness of ice. J Phys 1987;48:313-9.

[9] Schulson EM. The brittle compressive fracture of ice. Acta Metall Mater 1990;38:1963-76.

[10] Dempsey J. The fracture toughness of ice. In: Jones S, Tillotson J, McKenna R, Jordaan I, editors. Ice-structure interaction: Springer Berlin Heidelberg; 1991 p. $109-45$.

[11] Weber LJ, Nixon WA. Fracture toughness of freshwater ice - part I: experimental technique and results. J Offshore Mech Arct Eng 1996;118:135-40.

[12] Uchida T, Kusumoto S. Effects of test conditions on fracture toughness and fracture morphology of polycrystalline ice. JSME Int J Ser a-Solid Mech Mater Eng 1999;42:601-9.

[13] Dutta PK. Compressive failure of polycrystalline ice under impact. In: Chung JS, editor. Proceedings of the third (1993) international offshore and polar engineering conference. Singapore: The International Society of Offshore and Polar Engineers; 1993. p. 573-80.

[14] Dutta PK, Cole DM, Schulson EM, Sodhi DS. A fracture study of ice under high strain rate loading. Int J Offshore Polar Eng 2004;14:182-8.

[15] Kim H, Keune JN. Compressive strength of ice at impact strain rates. J Mater Sci 2007:42:2802-6.

[16] Hopkinson B. A method of measuring the pressure produced in the detonation of high explosives or by the impact of bullets. Philos Trans R Soc Lond Ser A 1914:213:437-56.

[17] Kolsky H. An investigation of the mechanical properties of materials at very high rates of loading. Proc Phys Soc Sect B 1949;62:676-700.

[18] Jones SJ. High strain-rate compression tests on ice. J Phys Chem B 1997;101: 6099-101.

[19] Shazly M, Prakash V, Lerch B. High strain-rate compression testing of ice Cleveland, OH: NASA Glenn Research Center; 2006. p. 95.

[20] Shazly M, Prakash V, Lerch BA. High strain-rate behavior of ice under uniaxial compression. Int J Solids Struct 2009;46:1499-515.

[21] Shazly M, Prakash V, Lerch BA. High strain rate compression testing of ice, paper \# 318 (s14). In: Proceedings of the 2005 SEM annual conference and exposition on experimental and applied mechanics. Bethel, Connecticut, USA, Portland, Oregon USA: Society of Experimental Mechanics; 2005. p. 359-65.

[22] Baker RW, Gerberich WW. The effect of crystal size and dispersed-solid inclusions on the activation energy for creep of ice. J Glaciol 1979;24:179-94.

[23] Shoii H, Langway CC. Comparison of mechanical tests on the dye-3, Greenland ice core and artificial laboratory ice. Ann Glaciol 1985;6:305.

[24] Song M, Baker I, Cole DM. The effect of particles on dynamic recrystallization and fabric development of granular ice during creep. J Glaciol 2005;51:377-82.

[25] Okada M, Liou N-S, Prakash V, Miyoshi K. Tribology of high speed metal-onmetal sliding at near-melt and fully-melt interfacial temperatures. Wear 2001;249:672-86.

[26] Irfan MA, Prakash V. Contact temperatures during sliding in pressure shear impact. In: Proceedings Society of Experimental Mechanics conference. Bethel, CT, Baltimore, MD: SEM; 1994. p. 173-82.

[27] Ullah H, Irfan MA, Prakash V. State and rate dependent friction laws for modeling high-speed frictional slip at metal-on-metal interfaces. J Tribol 2007; 129:17-22.

[28] Prakash V. Time-resolved friction with applications to high speed machining: experimental observations. Tribol T 1998;41:189-98.

[29] Graham DA. Specimen inertia in high strain-rate compression. J Phys D 1989;22:1888-93.

[30] Sunny G, Yuan F, Prakash V, Lewandowski JJ. Design of inserts for splitHopkinson pressure bar testing of low strain-to-failure materials. Exp Mech 2009; 49:479-90.

[31] Davies EDH, Hunter SC. The dynamic compression testing of solids by the method of the split Hopkinson bar. J Mech Phys Solids 1963;11:155-79.

[32] Frew D, Forrestal M, Chen W. Pulse shaping techniques for testing brittle materials with a split Hopkinson pressure bar. Exp Mech 2002;42:93-106.

[33] Sunny G, Prakash V, Lewandowski JJ. Effects of annealing and specimen geometry on dynamic compression of a Zr-based bulk metallic glass. J Mater Res 2007;22:389-401.

[34] Sunny G, Yuan F, Prakash V, Lewandowski JJ. Effect of high strain rates on peak stress in a Zr-based bulk metallic glass. J Appl Phys 2008;104:093522.

[35] Sarva S, Nemat-Nasser S. Dynamic compressive strength of silicon carbide under uniaxial compression. Mater Sci Eng a-Struct Mater Prop Microstruct Proc 2001;317:140-4.

[36] Shan R, Jiang Y, Li B. Obtaining dynamic complete stress-strain curves for rock using the Split Hopkinson pressure bar technique. Int J Rock Mech Min Sci 2000;37:983-92.

[37] Yuan F, Prakash V, Tullis T. Origin of pulverized rocks during earthquake fault rupture. J Geophys Res 2011;116.

[38] Subhash G, Ravichandran G. Split Hopkinson bar testing of ceramics. In: Kuhn H, Medlin D, editors. ASM handbook. Materials Park, OH: ASM International; 2000. p. 497-504.

[39] Kennedy FE, Schulson EM, Jones DE. The friction of ice on ice at low sliding velocities. Philos Mag a-Phys Condens Matter Struct Defects Mech Prop 2000;80:1093-110.

[40] Maeno N, Arakawa M. Adhesion shear theory of ice friction at low sliding velocities, combined with ice sintering. J Appl Phys 2004;95:134-9.

[41] Maeno N, Arakawa M, Yasutome A, Mizukami N, Kanazawa S. Ice-ice friction measurements, and water lubrication and adhesion-shear mechanisms. Can J Phys 2003;81:241-9. 